\title{
Vínculo e psicose: uma articulação entre a etnografia e a clínica psicoterapêutica ${ }^{1}$
}

\author{
José Bizerril* \\ Luanna Barbosa**
}

"Centenas de pessoas passaram diante de meus olhos carentes.

Nenhuma delas teve noçãoda piedade que havia na minha alma:atrás da ferida de cada olhar,parecia haver uma cacimba ocae profunda."

Arriete Vilela

“[...] receio começar a 'fazer' um sentido, com a mesma mansa loucura que até ontem era meu modo sadio de caber num sistema. Terei que ter a coragem de usar um coração desprotegido e de ir falando para o nada e para o ninguém? assim como uma criança pensa para o nada. E correr o risco de ser esmagada pelo acaso.”

Clarice Lispector

\section{Resumo}

O vínculo é uma ferramenta importante não só na construção do processo psicoterapêutico, como na produção de pesquisa, aqui referente a uma etnografia realizada no Instituto de Saúde Mental da Secretaria de Estado da Saúde do Distrito Federal. A metodologia qualitativa ressalta a importância do vínculo na relação entre pesquisador e pesquisado, para ambos a pesquisa deve ser geradora de sentidos (GONZÁLEZ REY, 2005a, 2005b). Ainda, o método etnográfico resgata da psicologia o conceito de vínculo (BIZERRIL, 2004), que, na clínica das psicoses, foi salientado pela antipsiquiatria. O objetivo deste trabalho

\footnotetext{
${ }^{1}$ Referente à pesquisa "Subjetividade, experiência e psicose", realizada no V Programa de Iniciação Científica do UniCEUB.

* Mestre e doutor em Antropologia Social pela UnB, professor do curso de psicologia do UniCEUB, coordenador do grupo de estudos interdisciplinares Diálogo (UniCEUB).

${ }^{* *}$ Graduada em psicologia pelo UniCEUB, mestranda em Antropologia Social pelo PPGAS (Programa de Pós-Graduação em Antropologia Social) da UnB, membro do grupo de estudos interdisciplinares Diálogo (UniCEUB).
} 
é discutir o vínculo com pacientes psicóticos, no imbricamento entre pesquisa e clínica psicoterapêutica, que se complementam como forma de compreensão do transtorno mental.

Palavras-chave: Vínculo. Vínculo etnográfico. Psicose. Antipsiquiatria. Reforma psiquiátrica.

\section{0 papel do vínculo na investigação qualitativa}

Autores da antipsiquiatria (COOPER, 1974, 1989, 1994; LAING, 1974, $1982,1988,1989,1991,1993)$, bem como aqueles com uma perspectiva antimanicomial (REICH, 2004; VASCONCELOS, 2003, 2005) têm ressaltado a importância do vínculo no manejo psicoterápico com pacientes ${ }^{2}$ com transtornos psicóticos ${ }^{3}$. Apesar da concepção difundida de que "o psicótico" não tem a possibilidade de enxergar o outro nem tampouco de vincular-se, esses autores demonstraram o vínculo como condição sine qua non no tratamento desses pacientes. Os resultados que obtive em minha etnografia com esses sujeitos apontam para essa perspectiva. A relação pesquisador-pesquisado, nesse trabalho, realizado entre agosto de 2006 e agosto de 2007, no Instituto de Saúde Mental da Secretaria de Estado da Saúde do Distrito Federal (ISM/SES), mostrou-se fundamental não só para o processo de pesquisa, como para minhas produções subjetivas e para as das pessoas entrevistadas.

\footnotetext{
2 Apesar de o termo paciente remeter ao campo do conhecimento médico, refletindo estigmas históricos e uma área restrita de atuação, com seu arcabouço teórico particular, darei preferência a ele em detrimento do termo "usuário", que me parece tentar introduzir uma quebra de paradigmas, sem ser acompanhada de ações efetivas e mascarando a mesma estigmatização arraigada acima referida. A humanização do discurso não pressupõe necessariamente a quebra das reificações.

${ }^{3}$ Uso aqui as expressões "psicose", "psicótico", "transtorno psicótico" sob rasura, na falta de outras melhores e também por não ser o objetivo deste trabalho a discussão das estruturas psicanalíticas nem das categorias psiquiátricas. A psicanálise lacaniana, por exemplo, apesar de apontar para a singularidade, está baseada em uma epistemologia com pouco poder de singularização, ao identificar o sujeito sob o rótulo de estruturas universais. De todo modo, como este trabalho foi feito em um hospital, em que meus interlocutores foram acessados por meio de seus diagnósticos em seus prontuários, não pude evitar essa problemática no decorrer do texto.
} 
A epistemologia qualitativa, desenvolvida por González Rey (2005a, 2005b), afim ao método etnográfico, enfatiza: a singularidade como fonte de produção de conhecimento; a implicação subjetiva de pesquisador e sujeito - com suas respectivas produções de sentido no processo da pesquisa; a imbricação entre pesquisa e clínica; e o vínculo. Para o autor, as informações necessárias podem ser compreendidas pelo pesquisador, e uma inteligibilidade, construída, por meio de um processo dialógico, da necessidade e do interesse do pesquisado dentro desse processo e da construção de um vínculo. Em uma pesquisa qualitativa, é necessário que tanto pesquisador, como interlocutor estejam engajados subjetivamente no processo de diálogo e de construção do conhecimento. González Rey (2005a, 2005b) analisa, em relação à formação do vínculo na pesquisa de campo, que a díade pesquisador-interlocutor produz uma narrativa que não parte exclusivamente de nenhuma das partes e que se constrói em uma instância em que ambos estão qualitativamente envolvidos de modo semelhante. Em relação ao vínculo, ressaltado por Bizerril (2004), por González Rey (2005a, 2005b) e por Reich (2004) - na clínica das psicoses, este aparece como fator preponderante para que haja uma relação dialógica. Reich (2004) e Laing (1988) afirmam, ainda, o amor pelo objeto de conhecimento como fator premente no momento da escuta.

A escuta diferenciada e atenta, como método, foi um elemento fundamental para o desenvolvimento do vínculo, da pesquisa em si, e parece-me ter trazido resultados terapêuticos para os pacientes, como discutido a seguir. Muitos pacientes, mesmo após o encerramento das entrevistas, sempre me procuravam para contar-me sobre o que vinha ocorrendo em suas vidas, mantendo, cada um, um tipo de relação comigo que não se encerrou com o final da pesquisa.

A clínica, particularmente, em saúde mental, confronta-nos com a alteridade, com o cuidar do outro, respeitando seu modo de estar no mundo, seu ethos. Nesse sentido, a empatia comparece como base fundamental, para além do vínculo psicoterapêutico. Segundo Bizerril (2004, p. 158), um desdobramento dessa reflexão é considerar a totalidade da situação de pesquisa, entendendo o etnógrafo não apenas como um cientista em interação com seu "objeto" mas também como um ser humano em um universo intersubjetivo. É principalmente por meio de relações humanas que ele tem acesso ao mundo, ao 
ponto de vista e à experiência de outros sujeitos, os 'seus' nativos. Isso tem dois desdobramentos: a importância das relações humanas como constitutivas da possibilidade de pesquisa qualitativa; a repercussão da experiência de campo sobre a subjetividade do pesquisador.

$\mathrm{O}$ autor usa o conceito de vínculo, proveniente da clínica, estendendo-o ao campo etnográfico. Entretanto, penso se não seria um momento de analisarmos o caminho contrário, ou seja, usar a experiência etnográfica como ponte para compreendermos melhor a clínica psicológica, na qual, como assinalei, defrontamo-nos tanto com o fenômeno da alteridade.

Gostaria de radicalizar a importância da dimensão humana da pesquisa ao examinar o caráter das relações entre o etnógrafo e seus interlocutores, não apenas como fator imponderável, mas também importante, uma característica crucial, sem a qual não ocorre a etnografia. Defino essas relações como "vínculo etnográfico", por analogia à terminologia utilizada na discussão da área clínica de psicologia, em que o estabelecimento de aliança, pacto ou relação de cooperação e confiança entre o etnógrafo e seus colaboradores nativos é indispensável para que ocorra a pesquisa. De um lado, o etnógrafo precisa de treinamento, de um tipo de escuta, de capacidade de observação altamente específicos, de familiarização com as teorias atualizadas e relevantes à pesquisa e de conhecimento do método etnográfico; de outro, depende do estabelecimento de ligações emocionais e relações de reciprocidade que lhe dão acesso ao universo de concepções, práticas e experiências dos nativos. Assim, compreendo essa relação como mais do que a perspectiva utilitária de "aliciar" o nativo para que se torne "informante" [...]. (BIZERRIL, 2004, p. 159).

A relação construída, tanto na pesquisa de campo como na psicoterapia, no meu entender, é sempre feita a dois, construída de modo artesanal e diário, de forma posicionada (nunca neutra) e refletida. Nessa relação intersubjetiva, comparecem pesquisador/ pesquisado, psicoterapeuta/ paciente, como sujeitos implicados subjetivamente no diálogo e na relação, de modo que há repercussões nas produções subjetivas de ambos. Além disso, não constituem os apontamentos diários ou semanais feitos pelo psicoterapeuta uma espécie de diário de campo, em que comparecem não apenas a descrição clínica e sintomatológica, como também as reflexões e vivências daquele que "atende", observa, "trata”? 
Segato (2003), tratando sobre a possibilidade de diálogo da psicanálise com a antropologia, faz um paralelo entre a etnografia e a clínica. Para a psicanálise lacaniana, a transferência é uma instância indispensável para o trabalho analítico; por outro lado, na etnografia, a "contratransferência" seria indispensável, visto que é a partir das reflexões e vivências do antropólogo que um texto de interlocução poderia ser elaborado. Enquanto a psicanálise estaria a priori amarrada à norma e à teoria, a antropologia estaria mais aberta às concepções do nativo, embora o antropólogo, como já foi extensamente discutido, traga consigo seu ethos e suas teorias. Nesse sentido, marco a necessidade de culturalizar o que a psicanálise traz como premissa universal. $\mathrm{O}$ espaço psicoterapêutico, além disso, como enfatiza González Rey (2007), deve envolver o trabalho não apenas na esfera individual, como em todas aquelas que compareçam como produtoras de sentido subjetivo para o sujeito. Desse modo, são trabalhados, não de forma causal e mecânica, os espaços familiar, escolar, de trabalho, de lazer, de todas as redes de relações que afetem de forma subjetiva o paciente.

Ainda com relação ao modo singular pelo qual é desenvolvida a relação etnográfica, é justamente por tratar-se de um processo dialógico e de implicação subjetiva mútua que a etnografia é sempre um texto de co-autoria; ainda, o discurso desenvolvido pelo etnógrafo nunca é neutro, ao modo de uma câmera que vai até o local de interesse, trazendo de volta imagens que reproduzam e retratem seus objetos (mesmo fotografias não estão isentas do ângulo pelo qual são feitas ou da luz presente na hora, por exemplo). O texto que o antropólogo apresenta a seus leitores, após o trabalho de campo, envolve sempre sua construção subjetiva, sua perspectiva teórica e, ainda mais, seus recortes. A edição do texto - que é produzido a partir do diário de Campo, das transcrições das entrevistas, das reminiscências pessoais do etnógrafo, de reflexões teóricas, de "textos" nativos e de citações bibliográficas - é sempre objeto de uma seleção individual. Daí a noção do texto etnográfico como uma montagem (bricolage). Além disso, é sempre importante salientar, como aponta Tyler (2003), a importância da fala do etnógrafo não se tornar monológica, reproduzindo sua visão e seus interesses, ainda quando o sujeito da pesquisa o contradiga. A etnografia é um gênero do discurso; como um romance, comporta vários tipos de falas e de linguagem; é um gênero polifônico e heteroglótico. 


\section{A experiência de pesquisa}

Com relação ao vínculo etnográfico, meus entrevistados poderiam ser descritos na categoria típica do sujeito subalterno que não pode falar. No ISM, fui inscrita ${ }^{4}$ pelos pacientes na posição de um sujeito exterior à rede da instituição. Meu posicionamento, nesta, deu-se em um espaço que não é nem o do paciente, que partilha de suas experiências - o que observei quando me mostrei empática em relação ao estigma sofrido por um paciente, e percebi que, por mais que eu já houvesse sofrido qualquer tipo de estigma, aquele experimentado pelo paciente portador de diagnóstico é extremamente singular-; nem o do visitante, que comparece com os olhos externos da curiosidade e da relativa falta de informação; nem tampouco o de membros da equipe, mesmo os mais abertos, que têm voz de polícia, que ocupam uma posição que traz as relações paralelas de cuidado e poder/autoridade, ocultando os sentimentos de medo pela incompreensão e pela não legitimação do discurso e da experiência. Como pesquisadora, eu ocupava a posição de um sujeito que estava aberto a ouvir sua experiência, sem propósitos de tratamento ou de cuidado, ou seja, sem objetivos quaisquer comprometidos com o sistema. Assim, eu podia ouvir críticas a este (e no caso das críticas, isso também foi válido para os entrevistados da equipe), isentas do medo, bem como relatos de experiências que poderiam ser consideradas bizarras.

Desse modo, como pesquisadora, em alguns momentos, devido a uma escuta diferenciada, fui inscrita na posição do ouvinte atenta a experiências que, no âmbito da instituição, em geral, não são fatores de interesse comum. Os entrevistados sempre me cumprimentavam, sorriam, brincavam, perguntavam pela pesquisa, demonstravam atenção e interesse pela minha figura e solicitavam entrevistas. Uma paciente sempre perguntava quando poderia "conversar" comigo. No final de sua última entrevista, quis desligar-se da pesquisa pelo fato de que seus relatos eram dolorosos para ela, mesmo que eu observasse que o convite para a entrevista referia-se apenas ao que ela quisesse abordar; então me disse que se não falasse sobre suas dores eu não poderia "fazer um estudo de sua pessoa" e falou, preocupada com meu trabalho, que eu poderia utilizar o material que já tinha. Outro paciente sempre sorria para mim no ISM e relatava, nas

\footnotetext{
${ }^{4} \mathrm{~A}$ inscrição refere-se ao posicionamento do pesquisador assumido no campo, decorrente da negociação com as expectativas e perspectivas do nativo.
} 
entrevistas, que gostava de ser "ouvido e perguntado", como com os médicos e psicólogos. E outro sempre se aproximava de mim para ser entrevistado e sentia saudades das "conversas": "Tô com saudades de você. [...] Conversar com você. [...] É bom. Desabafa, né? [...] E você, tá realizando um ótimo trabalho? [...] Vai conseguir". Esse mesmo paciente surpreendeu-me, quando não só compartilhava comigo suas dores em relação à experiência do "ser psicótico" - na família, no âmbito social, no ISM - como quando me disse: "Eu vou revelar um segredo pra senhora". E abriu-me sua vida afetiva e sexual. Do mesmo modo, outro paciente sempre se aproximava, solicitava entrevistas e, certa vez, disse-me que iria revelar um segredo que só eu poderia ouvir, e, no meu ouvido, relatou alguns detalhes de sua experiência sexual. De modo geral, todos os pacientes que participaram da pesquisa estavam sempre abertos e interessados, sendo a escuta um fator fundamental.

Em outros momentos, ainda, por tratar-se de pacientes com história de internação, a entrevista assumia, na perspectiva do paciente, uma "função terapêutica”, demonstrada em vários momentos do trabalho. Existiu uma profundidade de vínculo que se deveu ao fato de eu ocupar, como pesquisadora, a posição liminar que discuti - nem uma pessoa da equipe, nem um sujeito "de fora". A entrevista se tornou um espaço de escuta social e terapêutica - mesmo que minha função fosse explicitada e mesmo que eles demonstrassem sabê-lo, minha posição, era, por vezes, confundida com a de psicóloga. Ainda durante o trabalho desenvolvido, registrei uma fala que exemplifica isso:

É bom pra pessoa conversar [as entrevistas]. [...] Não converso com ninguém, só converso com a senhora. [...] Pra me isolar. É difícil se aproximar das pessoas. E principalmente lá em casa, fala que eu tô conversando demais, aí eu paro logo. Pergunta logo se eu tô tomando remédio. [...]

É interessante notar que a escuta atenta e não dirigida ao sintoma permitiu aos pacientes aprofundar temas que muitas vezes não eram tratados com a própria equipe ou com a família. O paciente cuja fala citei acima e vários outros (como se pode observar na fala da paciente que retomou seus estudos, citada abaixo) tinham um espaço de escuta em que sua fala possuía legitimidade, fora da escuta manicomial que lhes é geralmente dada. 
Outra paciente, em sua última entrevista, mencionou que estava voltando a trabalhar:

- Agora eu estou desenvolvendo novas pinturas, muitos quadros diferentes.

- Que bom!

- Eu agora estou um rojão!

- Um rojão vivo?

- Um rojão vivo!

Essa paciente, em uma de suas entrevistas, havia mencionado que era um rojão morto. E, entre todos, emocionou-me muito uma das pacientes mais comprometidas, à época das entrevistas, que havia parado todas as suas atividades em função do transtorno psíquico, diagnosticado como esquizofrenia paranóide. Ela me procurou meses após o encerramento das entrevistas e trouxe-me esta fala:

Eu quero agradecer a você por você ter me escutado nos meus momentos mais difíceis, numa época em que ninguém me escutava, em que as pessoas só diziam que tudo aquilo era coisa da minha cabeça, que eu fosse tomar o remédio. Porque as pessoas só escutam com estigma. $\mathrm{E}$ você me gravou com o mp3. Eu quero dizer a você que eu terminei química, e só falta uma prova para eu terminar física. No outro semestre eu vou começar psicologia. Eu procurei você para dizer que consegui isso, e eu vou lhe procurar para contar isso quando isso acontecer.

Aqui também quero ressaltar que o gravador, que, para mim, era um mero instrumento de trabalho, para ela, assumiu valor significativo como objeto que gravava sua voz, que registrava sua fala, em um contexto no qual esta era absolutamente deslegitimada na família, nas redes sociais e na instituição. A escuta que não registra o discurso do sujeito no âmbito sintomático, mas que é, sim, continência para a fala do outro, é o ponto de partida para o desenvolvimento de uma relação sadia e igualitária. Laing (1974, 1982, 1988, 1989, 1991, 1993) apontou exaustivamente em seus trabalhos a função de escutar de forma atenta a fala e a experiência do paciente. Isso é também ilustrado pelo fato de que muitos pacientes solicitavam entrevistas por eles próprios, e outros ficavam felizes pelo fato de serem ouvidos e compreendidos em suas experiências. 
Até haver a mudança de chefias no ISM, no início de 2007, e algumas reuniões com o objetivo de discutir a mudança de funcionamento da instituição, observei, em todos os discursos dos funcionários, queixas e críticas veladas ao funcionamento do ISM, como comparece na fala de uma psicóloga da equipe ${ }^{5}$ :

[...] então o dia-a-dia era dividido por todos, os médicos jogavam futebol com eles [...]. é quando a gente se reunia toda semana, quando a gente tinha grupo de terapia toda semana $[. .$.$] no dia-a-dia, muito mais gostoso do que é$ hoje.

Ou no discurso de um psiquiatra que atuou no hospital-dia ${ }^{6}$, no início da década de 1990:

No meu tempo, havia maior disponibilidade de funcionários, havia uma equipe mais coesa. Ainda era uma coisa um pouco experimental, mas as pessoas ficavam muito debruçadas em cima desses assuntos. O número de pacientes era menor. Então a gente tinha um convívio muito mais [...] individualizado, mais cuidadoso, acho que mais detalhado com os pacientes, né? Então a gente discutia os casos quase todo dia, a gente reunia quase todo dia, a equipe tava muitas vezes reunida, né? Daí tinha um lugar bastante unido pros pacientes. [...] A coisa, eu acho que, deve ter tido grandes perdas também, agora, eu não tenho como avaliar. [...] A gente tinha assistente social, tinha psicólogo, tinha enfermeiro, tinha auxiliar de enfermagem, tinha muito estagiário. Então tinham muitos

${ }^{5}$ Em meu trabalho, por questões éticas, não identificarei em absoluto quaisquer dos membros da equipe nem dos pacientes entrevistados; no caso da equipe, isso é justificado por eventuais críticas que possam comprometer a política administrativa da instituição, cujo objetivo não se inseriu em minha pesquisa; no caso dos pacientes, o sigilo me parece ainda mais rigoroso, não só no que se refere a críticas e queixas, como ao detalhamento biográfico e sintomático.

${ }^{6} \mathrm{O}$ ISM se divide em um hospital-dia, que funciona das $8 \mathrm{~h}$ às $17 \mathrm{~h}$, com oficinas e atendimentos em grupo e individuais, recebendo pacientes neuróticos graves e psicóticos; um ambulatório, que atende pacientes neuróticos e pacientes com alta ou pré-alta do hospital-dia; e duas enfermarias, que receberam parte dos pacientes advindos da extinta Clínica Planalto, desmantelada pelo Governo por maus-tratos. O projeto da instituição é transformar sua estrutura em um CAPS que referencie a região que atende; e acabar com as enfermarias, transformando-as em residências terapêuticas, de acordo com a proposta do Ministério da Saúde. A regional do ISM atende as seguintes cidades-satélites, em princípio: Candangolândia (cerca de 25 mil habitantes); Núcleo Bandeirante (cerca de 55 mil habitantes); Riacho Fundo (cerca de 65 mil habitantes); Recantos das Emas (cerca de 120 mil). 
profissionais. Hoje eu sei que tem pouco assistente social, tem poucos psicólogos. Então, tá tendo umas dificuldades aí. Mas, era muito bom, a gente podia trocar, cada um na sua ótica, né? Ver o paciente. Então era muito rico. Acho que era, ajudava bastante.

Uma psicóloga entrevistada por mim narrou esse tempo nostálgico, mencionado por vários funcionários, em que a instituição tinha um projeto e um funcionamento diferentes: visitas domiciliares mais regulares, reuniões de equipe freqüentes, intenso intercâmbio entre equipe e pacientes. A esse respeito, comenta que o vínculo é um fundamento substancial para a melhora dos pacientes, e que era no desenvolvimento das relações entre técnicos e aqueles que as experiências se davam de forma radical:

[...] às vezes nem mudava a medicação ainda, nem tinha atendimento médico ainda, já mudava, pela questão do vínculo. Então eu vejo que, quando a gente trabalha mais o vínculo, a coisa flui muito mais do que coisas específicas. [...] A gente já teve pacientes aqui mais crônicos e que tão muito bem hoje, porque a equipe foi na casa deles, fez um trabalho de acompanhamento terapêutico, de organizar casa, de caminhar com eles, de ensinar eles a fazerem as coisas.

A referida psicóloga desenvolveu de forma extensa o papel que a instituição cumpria, há alguns tempos, no sentido de dar suporte às demandas dos pacientes, utilizando-se, para isso, principalmente, do vínculo, da ressocialização e do trabalho interdisciplinar. O manejo da transferência, a convivência e as trocas afetivas e sociais eram pedras angulares do tratamento no ISM. Sobre esse período e sobre essa função terapêutica, a psicóloga menciona:

Os momentos melhores [...] é quando a gente se reunia toda semana, quando a gente tinha grupo de terapia toda semana [discurso de muitos antigos na equipe], [...] e tinha psicólogo que participava das atividades de convivência com pacientes, era nesses momentos que o vínculo se estabelecia muito mais fácil, e que a gente entendia o paciente muito melhor [...] hoje em dia o psicólogo, o contato dele é muito menor do que anos atrás. [...] as famílias vinham, era toda semana, [...] agora não. [...] A melhor época também foi quando eu participei de um grupo, chamado grupo de inserção. O paciente chegava, oito pacientes de uma vez, aí ficavam nesse grupo quinze dias ou três semanas. E a gente fazia tudo junto com o 
paciente [...] E isso eles melhoravam rapidamente [...] Teve um paciente que ele era um professor de outro estado e ele tava muito deprimido. Chorava [...], parecia um bebê. [...] De repente ele, um dia "ah, vou voltar pro meu estado" e tal, aí [...] voltou a ensinar. Ele precisava daquele momento. [...] de se expressar, de regredir e ter continência pra isso, já tive mais de um assim que saiu muito bem. Mas tinha espaço. [...] teve um paciente aqui que era crônico, no final a mãe viajava, e ele ficava tomando conta da casa, ia no banco pra mãe, fazia compras, então tem um paciente aqui que passou 40 anos num hospício em Goiânia, chegou aqui, [...] nem chamava meu nome, mas a irmã que tomava conta dele, muito interessada, ela já conseguia que ele fosse no supermercado comprar alguma fruta pra ela. Então quando você realmente cuida da ressocialização [...] por mais crônico que ele esteja, a coisa caminha. [...] eu vejo o psicótico muito como aquele que o vínculo é muito frágil ${ }^{7}$ [...] é importante ele se sentir útil [...].

A respeito da instituição como tendo papel de recolhimento e agenciamento da transferência, Tenório (2001, p. 69) afirma, em oposição a um sistema de referência terapêutica individual, que o "tecido institucional" exerce uma função específica, na medida em que:

7 Nesse sentido, observo que, de forma geral, pacientes com transtornos psicóticos podem ter vínculos frágeis, em seu cotidiano, devido ao modo como se deu sua história e, principalmente, ao fato de seu discurso e seu comportamento não se inserirem na esfera do que é considerado normal, tratando-se de uma questão social, e não um sintoma, a priori, da psicose, como mencionei no início deste artigo. Com relação à legitimidade de enquadrarem-se tais pacientes como esquizofrênicos, discuto os itens A.5 e B. do DSM-IV-TR (p.315-316), que se referem, respectivamente, aos sintomas negativos, como o embotamento afetivo, e às perturbações nas relações interpessoais. Dois pacientes com diagnóstico de F-20 (esquizofrenia) são ilustrativos no que se refere a esse tema: em suas falas, sempre compareciam o cuidado com o outro - familiares ou mesmo desconhecidos. O embotamento afetivo pode ser pensado como ausência de emocionalidade observada na forma do paciente expressar-se e comportar-se, mas esse cuidado com o outro não é uma forma de emocionalidade conectada com a "realidade"? Justamente, somado ao insight primário, essa atenção que tais pacientes têm com o bem-estar dos outros são indicadores de outra posição do que a caracterização clássica do "psicótico". Isso vai de encontro à posição comum de que o psicótico não consegue estabelecer relações nem vínculos com o outro. Ainda mais, foram pacientes que, do início ao fim, e mesmo após a pesquisa, apresentaram excelente vínculo comigo, bem como outros, preocupando-se inclusive com meu bem-estar e com meu trabalho. 
[...] os lugares concretos contam pelo que permitem de reorganização do espaço, e toda pessoa que trabalha na instituição está investida de um "coeficiente psicoterápico". [...] a própria concepção de instituição passa a se orientar pela idéia da transferência como centro do trabalho, e a noção de "coletivo" é elevada à condição de conceito organizador do espaço terapêutico.

\section{A legitimação da voz do paciente}

Freud sempre apontou a importância da transferência, em primeiro lugar, como um processo agenciador da mudança no trabalho analítico. Esse conceito, trabalhado pelos membros da equipe, pode ser estendido ao tratamento institucional, como mencionado por Tenório (2001), ou mesmo à pesquisa de campo. Entretanto, para além do conceito de transferência, ressalto, com base na perspectiva do relativismo cultural e em direção a uma visão antipsiquiátrica, a relevância de considerar-se a experiência do outro pela sua ótica, distanciando-se da lógica que rege aquilo que é compartilhado pela subjetividade social como normal. É justamente pelo fato de que adotei uma postura e uma visão existencial e fenomenológica, conferindo lugar primordial à voz e à experiência de meus entrevistados, que cada relação foi única. O papel que assumi para cada um deles é único, como o é o que cada um deles assumiu para mim, considerando-se o vínculo e as subjetividades envolvidas no desenrolar das relações.

Como aponta Foucault (2004, p. 187):

A evidência do "este aqui élouco", que não admite contestação possível, não se baseia em nenhum domínio teórico sobre o que seja a loucura. Mas, inversamente, quando o pensamento clássico deseja interrogar a loucura naquilo que ela é, não é a partir dos loucos que ele o faz, mas a partir da doença em geral. A resposta a uma pergunta como "Então, que é a loucura?" é deduzida de uma análise da doença, sem que o louco fale de si mesmo em sua existência concreta.

Apesar de esse posicionamento ter surgido na modernidade, ele ainda se mantém na atitude e no discurso contemporâneo. Relacionar-se com o sujeito, dialogar com a voz que reflete sua subjetividade, e não com sua etiqueta, é um passo na humanização desse ser demasiadamente humano que por tanto tempo assumiu 
(e assume) o lugar de lixo social. Perceber a fala e o comportamento do psicótico como imbricados à sua experiência, e não como sinais jogados num mapa de anamnese para acertar um diagnóstico, pode constituir-se na tarefa mais humana na escuta a esses sujeitos, ainda que nomeá-los como "esses", "o paciente”, “o psicótico" etc, bem como a diferenciação que se interpõe na clínica e na pesquisa do outro como objeto a ser compreendido, seja uma forma radical de assimetria na relação. Como afirmam Laing (1988) e Reich (2004), é preciso que nosso objeto de estudo seja também um objeto de amor. Entretanto, como apontado por Rotelli et al (2001, p. 61), "o manicômio é o lugar zero da troca".

Aqui eu delineio, para além da importância, a dificuldade que se sente, na maioria das vezes, em construir-se um vínculo sólido com pacientes com transtornos psicóticos. Em geral, o homem comum, ou, como conceituado por Reich (2004), o Homo normalis, recusa-se a entrar em contato com as esferas mais arraigadas em seu inconsciente, que denunciam suas dificuldades e misérias humanas. O psicótico é aquele que se atreveu a mostrar, no cenário público, aquilo que é rejeitado como bizarro, sujo, insano. Em uma sociedade que pretende manter seus núcleos de relações a-contraditórios, esses sujeitos se afiguram como refugo social (BAUMAN, 2005), como estranhos, como sujeitos que mancham os mapas estético, cognitivo e moral da sociedade (BAUMAN, 1998). A negação em avaliar, em si próprio, aquilo que é apontado nesse outro como diferente, temido ou mesmo terrível é uma das causas, não só no âmbito do senso comum, como entre profissionais, de conceder a essas pessoas a posição de lixo social (quando estas não se tornam, mesmo, invisíveis), impedindo qualquer tipo de troca ou vínculo humano. Segundo Reich (2004, p. 369-420):

[...] o esquizofrênico é perturbadoramente honesto. Também é o que se costuma chamar de "profundo" [...]. A pessoa esquizóide vê através da hipocrisia e não esconde tal fato. Tem uma excelente compreensão das realidades emocionais, em evidente contradição com o homo normalis. [...] Essas grandes almas, derrotadas e aniquiladas enquanto "esquizofrênicas", CONHECEM e PERCEBEM aquilo que o homo normalis não ousa pensar. [...] Tiveram a coragem de se aproximar daquilo que se costuma evitar e foram destruídas porque atravessaram o inferno sem nenhuma ajuda [...]. 
Nas palavras de alguns sujeitos com transtornos mentais:

[...] está todo mundo dentro de um saco de milho de pipoca, só que o louco é a que estoura primeiro. A loucura é geral, a situação está ruim, só que a gente estoura primeiro, porque somos mais vulneráveis, só isso, nossa diferença é essa. (MEDEIROS NETO apud VASCONCELOS, 2005, p. 146)

Ainda,

[...] Nós somos uma referência da subjetividade humana mais profunda. $\mathrm{O}$ mundo de hoje é um mundo em que os fatores irracionais são muito importantes. Então, somos nós quem vive mais essa experiência de lidar com o inconsciente, de lidar com a loucura. (FREIRE apud VASCONCELOS, 2005, p. 80)

Segundo um autor que, diante do boicote editorial a respeito da reunião de narrativas em primeira pessoa de pacientes mentais, ousou fazer uma publicação independente,

[...] a diferença mais profunda [...] é a de que estes nossos semelhantes, que convivem de forma mais permanente com a possibilidade desses estados radicais de existência, têm a tarefa ontológica de nos relembrar, por mais que queiramos rejeitá-la, a nossa condição básica comum de sujeitos do inconsciente e da pulsão. [...] [o relato das vivências capacita-nos a ser] porta-vozes mais universais destas dimensões recalcadas do ser e reclamarem mudanças concretas na forma como a sociedade encara e trata destas dimensões e destas pessoas, nas suas teorias da subjetividade, nos serviços de saúde mental e no conjunto da vida social. (VASCONCELOS, 2005, p. 16-17)

Vasconcelos (2003) aponta as narrativas pessoais de vida como uma das formas de ressignificar e dar novo sentido às vivências subjetivas da experiência com o transtorno mental. Tais narrativas em primeira pessoa, como as citadas aqui por mim, são de cunho representativo justamente por trazerem a voz do paciente acerca de seu sofrimento. As narrativas pessoais têm importância não apenas como modo de gerar novos sentidos para o sujeito acerca de sua vivência, como de compartilhar sua experiência com outros pacientes, além de ser uma tentativa de superação de meta-narrativas, trazendo, com a voz ativa do paciente, uma representação política e social. A voz do sujeito em primeira pessoa é um ponto de partida para a representa- 
ção de um grupo tão marginalizado, e é por sua legitimidade como afirmação da experiência subjetiva e como expressão de uma experiência tão radicalmente dolorosa e transformadora que escolhi o método etnográfico para esta pesquisa.

Tais narrativas, organizadas pelos próprios autores ou reunidas em trabalhos literários ou científicos, não só inscrevem o discurso do psicótico no cenário social, como levam ao público esse tipo de experiência tão marginalizada por fugir à esfera do normal. A inscrição do sujeito psicótico no social é um ponto de partida imprescindível para minimizar o impacto do sofrimento causado a essas pessoas pelo cenário normativo e massificador, que atravessou nossa história, como analisado por Foucault (2004). Ao aliar o trabalho de campo ao trabalho clínico, pesquisas deste tipo, num registro não monológico que confere voz ao sujeito, são contribuição valiosa para a compreensão e o trabalho com psicóticos. E, para isso, como discutido por mim, o vínculo é o meio mais poderoso.

\section{Bond and psychosis: an articulation between ethnography and the psychotherapeutical clinic}

\section{Abstract}

The bond is an important tool not only in the construction of the psychotherapeutical process as it is in the production of a research, here in reference to an ethnography done in the Instituto de Saúde Mental (in Brasília). The qualitative methodology stands out the importance of the bond in the relationship between researcher and researched, both of which must be involved in the research (GONZÁLEZ REY, 2005a, 2005b). Still, the ethnographic method retrieves from psychology the concept of bond (BIZERRIL, 2004) that, in the clinic of psychosis, was pointed out by the antipsychiatry. This article aims at discussing the bond establishing with psychotic patients, in the imbrication between research and psychotherapy, that complement each other as a way of comprehending the mental disorder.

Keywords: Bond. Ethnographic bond. Psychosis. Anti-Psychiatry. Psychiatric reform. 


\section{Referências}

AMERICAN PSYCHIATRIC ASSOCIATION. DSM - IV - TR - Manual diagnóstico e estatístico de transtornos mentais. 4.ed. Porto Alegre: Artes Médica, 1995/2002.

BAUMAN, Z. O mal-estar da pós-modernidade. Rio de Janeiro: Jorge Zahar, 1998.

. Vidas desperdiçadas. Rio de Janeiro: Jorge Zahar, 2005.

BIZERRIL, J. O vínculo etnográfico: intersubjetividade e co-autoria na pesquisa qualitativa. Universitas Ciências da Saúde, Brasília: UniCEUB, v. 2, n. 2, 152$163,2004$.

COOPER, D. A morte da família. São Paulo: Martins Fontes, 1994.

. Gramática da Vida. Lisboa: Presença, 1974.

. Psiquiatria e Antipsiquiatria. São Paulo: Perspectiva. 1989.

FOUCAULT, M. A história da loucura na idade clássica. São Paulo: Perspectiva. 2004.

GONZÁLEZ REY, F. Pesquisa qualitativa em psicologia. São Paulo: Thomson, 2005.

. Pesquisa qualitativa e subjetividade: os processos de construção da informação. São Paulo: Thomson, 2005.

2007.

. Psicoterapia, subjetividade e pós-modernidade. São Paulo: Thomson,

LAING, R. D. A política da experiência e a ave do paraíso. Petrópolis: Vozes, 1974.

Vozes. 1988.

A voz da experiência: experiência, ciência e psiquiatria. Petrópolis:

. El yo dividido. Madrid: Fondo de Cultura Econômica, 1993.

. Fatos da vida. Rio de Janeiro: Nova fronteira. 1982. 
. Laços. Petrópolis: Vozes. 1991.

O eu e os outros. Petrópolis: Vozes. 1989.

REICH, W. Análise do caráter. São Paulo: Martins Fontes. 2004.

ROTELLI F. et al. Desinstitucionalização. São Paulo: Hucitec, 2001.

SEGATO, R. L. Las estructuras elementales de la violencia. Buenos Aires: Universidad Nacional de Quilmes Editorial, 2003.

TENÓRIO, F. A psicanálise e a clínica da reforma psiquiátrica. Rio de Janeiro: Rios Ambiciosos, 2001.

TYLER, S. La etnografía posmoderna: de documento de lo oculto a documento oculto. In: REYNOSO, C. (Org.) El surgimiento de la antropología posmoderna. 5 ed. Barcelona: Gedisa, 2003.

VASCONCELOS, E. et al. Reinventando a vida. Rio de Janeiro: EncantArte, 2005.

VASCONCELOS, E. O poder que brota da dor e da opressão. São Paulo: Paulus, 2003. 